\title{
Research on the Role of University Sports Development Training on College Students' Social Adaptation
}

\author{
Wei Liu \\ Hunan Vocational College of Modern Logistics, Changsha, Hunan, 410131
}

Keywords: social adaptation; university sports development training; role

\begin{abstract}
Outward training has unique effects and advantages in improving stress tolerance, facing psychological setbacks, interpersonal communication, teamwork, and exploring innovative social adaptation capabilities. Based on previous practice and through theoretical research, this paper explores the relationship between outward training and mental health and social adaptability of college students, and aims to establish and improve university sports development training courses, and expand training content in other courses for reference.
\end{abstract}

\section{Introduction}

The era of knowledge economy is not only a competitive era but also an era of cooperation and an era of common development. To be invincible in competition, we need to be well adapted to this era. To keep up with the pace of social development, we must learn to respect each other, learn to listen to the opinions of the team, and learn to have our own. The judgment of things, these are the basic skills that today's college students should master, this article is through the development of training on the college students' outlook on life, good collectivism and team awareness to shape well, change their bad habits, thus increasing the current and Future social adaptability [1].

The university stage plays a very important role in the development of an individual's life. It is the period of transition and preparation for individuals from adolescence to adulthood. It is a transitional and preparation period from learning to work. Individuals' adaptability to college not only affects their college-level study and life, but also affects their adult work and life. Faced with being unable to successfully enter the work role after graduating from college, they cannot timely adjust their mentality and correctly handle the human relations at work. They even use their brains to influence their work [2]. They cannot find an entry point to integrate into the work environment, causing confusion, depressing and detours. -3 years of energy wasted on the transition of students to work roles. Teamwork spirit is the necessary individual qualities from the study-oriented to work-based transitional period. It provides an important and major spiritual energy reserve for the smooth transition of roles. In the face of a rapidly developing society, it is essential to have a good sense of teamwork. The level of team cohesion directly represents the working ability of a working group unit and the potential for sustainable development. In the current curriculum setting of higher education, how to effectively improve students' social adaptability through higher education and cultivate a good team spirit has become crucial. The cultivation of good social adaptability is the key to education, especially college education. As an experiential teaching method that mainly uses the method of team training to develop the quality of the teaching model, it is possible to maximize practical teaching. In particular, in addition to professional skills, contemporary college students can quickly adapt to the spiritual aspects of social life and observe professional ethics. To cultivate team sense of belonging teaching. The purpose of this article is to cultivate the team spirit and social adaptability of the undergraduates through the development of the training model. In the process of physical education learning, they should establish harmonious interpersonal relationships and build a good spirit of cooperation and team while learning skills and physical fitness. Consciousness, to enhance their social adaptability, so as to achieve the effect of practical teaching can not reach the normal teaching, perfect the purpose of quality education in the true sense. Enhance the social adaptability of undergraduate students, especially for the enterprises and institutions to cultivate a strong sense of teamwork. Put forward requirements: As a matter of improving the overall quality, 
the teaching content of the relevant team should be taken seriously [3]. It is imperative for quality development training to enter colleges and universities.

\section{Research Objects and Methods}

Objective of the experiment: To extend training by adding independent variables to the experimental class, and to compare the social adaptability and class cohesion of the students of the control class after one semester of study, and to analyze the influence of the extended training on college students' social adaptability and class cohesion. Subject: Hebei Province Women's Vocational and Technical College 2010 social work department nursing class 1 for the experimental class 29 people, the control class for the care of 3 classes total 29 people, both classes are girls. Experiment period: 12 weeks, once a week, 90 minutes each time. Experimental location: Hebei Women's Vocational and Technical College Stadium. Test Tools: "College Class Cohesion Questionnaire" and "Social Resilience Diagnostic Questionnaire" "College Class Cohesion Questionnaire" is Xiong Jiao's preparation of a survey questionnaire specifically for college class cohesion. It consists of five dimensions [4]: organizational identity and management support. , interpersonal harmony, team performance, and group participation, including a total of 25 options, all projects have a higher degree of meaning and familiarity, through the project analysis and factor analysis after the prediction, also deleted a part of the items that do not meet the requirements, including organizations Identities consist of 6 questions 1-6 questions, management support includes 5 questions 7-11 questions, interpersonal harmony includes 6 questions 12-17 questions, and group participation includes 4 questions 18-21 questions. Team performance includes 4 items 22-25 questions each item is $1-5$, and the corresponding score is $1,2,3,4,5$. This study uses the "Social Adaptability Diagnostic Scale" compiled by Professor Zheng Richang, a professor of the School of Psychology at Beijing Normal University, and a test scale for social adaptability. It includes five dimensions of group music, self-confidence, responsibility, and social acceptance. Sexual and adaptive flexibility. The scoring criteria are: Options 1, 2, 3, 4, and 5 correspond to 1, 2, 3 , 4, and 5 points in sequence.

\section{Results Analysis}

The contrast class passed one semester of aerobics learning. We can see the differences in social adaptation before and after the semester. There are no significant differences between the four aspects of the music group nature, sense of responsibility, social acceptance, and adaptability flexibility. Through one semester of study, there are significant differences, and the difference is significant. Aerobics not only promotes people's physical health, but also promotes good physical and temperament, cultivates the correct aesthetic point of view, and cultivates the sentiments of the United States. As a result, students have more self-confidence, and attitude toward life is positive. Development has significantly improved self-confidence in social adaptation. However, the learning of aerobics is not very obvious for other aspects such as the group's nature and sense of responsibility. This is because aerobics is classified as a difficult-to-be-featured sports item in sports training. It is a closed-form skill in sports psychology. Therefore, in learning, it is more of a foreseeable environment. There is not much cooperation with other people, and more reflects the performance of the self. It is not obvious in terms of teamwork. Only one semester of study, the students can not reach the point where they can cooperate with each other to perform collectively. Through a semester of aerobics learning, there was no significant difference in group sex, sense of responsibility, social acceptance, and flexibility of adaptation [4].

Aerobics is a kind of sport that promotes individuality and expresses oneself. It is expressed through the language of the body. After adding an aerobics learning to an aerobics class, the students' self-confidence not only originates from itself but also originates from the collective and strengthens itself. The collective sense of honor. Extensive training itself is a kind of psychological training method that takes personal experience as the core, and exerts interventions on people's deep psychological through various project activities. It can break through the psychological barriers of 
people, increase the sense of collective honor, and enhance the sense of mission. Cohesion, people from the game to experience the invisible personal relationships in daily life or work and the role of the team, after each activity, seriously reflect on, and actual life, work, learning resonance, so as to achieve the purpose of training. As students expand each time they practice, the distance between people is getting closer, creating opportunities for more contacts to understand each other. When each task is successful, students will develop a deeper sense of dependence on the group, and one A good collective will in turn give students more rewards, and thus form a virtuous circle. This is why students' musicality before and after the experiment has greatly improved. For example, in the extended practice of concentric circles, the purpose of this exercise is to allow students to experience team spirit, require each student to obey the command, participate actively, and require everyone in the team to contribute their own strength. There is an idea of being lazy or indiscriminate. This requires cooperation between students. Each member must use his or her own abilities to cooperate with the group to complete the task. Individualism will eventually lead to the failure of the task. Therefore, in practice, students are invisible. China will increase its sense of responsibility. For the sake of collective success, it will sacrifice its own interests for the time being. In daily life, it will also realize the importance of team awareness. When it comes to situations like teamwork, it will be relatively mature. Treatment methods improve the students' social adaptability. For example, in an excellent dormitory appraisal or a party held in a class, these group activities are no longer the responsibility of the headmaster or the head of the class leader. Instead, they are brainstorming. Under the leadership of the headmaster or squad leader, they will exert their own strength and work for the collective. Honorary advice [5].

When a group has students with weaker individual abilities, each person's attitude is different. Some students will take their noses, some students will respect them, and some students will help them with care. This is everyone's social acceptance. For example, in the practice of the six-man seven-legged race, there are students who are good at running, students with poor athletic ability, have tempered temperament, chronic children, students who are eager to win, and students who are full of enthusiasm, and the quality of a middle school student. The personality is uneven, if there is no unified command, no teamwork, can not go to the end, through this practice method, students learn to be inclusive, active ability to slow down and make the team to form a rhythm; anxious classmates with arrogance and arrogance, they collapsed and came to the end step by step. The students who used to enrich their skills increased their collective vision. The students found in the exchange of ideas to discover the potential of each person. Everyone has their own advantages, but they themselves and others do not find it in time. The collective formed by every classmate is indispensable, either in the team or in leadership. The person or the executor must display the potential of each person. It is also one of the goals of the exercise itself and is good at discovering the merits of others. The students' social acceptance ability was improved invisibly, and students' self-centered consciousness in the dormitory was changed. Students actively understood the classmates and accepted the group and fundamentally changed the collective appearance. The group is made up of many individuals. Individuals should actively adapt to the group rather than let the group adapt to themselves. In each class, some classmates have poor adaptability and can't always adjust their minds to go to work. The rhythm of most of the students, through 12 weeks of expansion exercises, gradually opened their minds to these students and actively adapted them. When problems were encountered, they would not complain about the external environment blindly. Instead, they first looked at their own problems and showed themselves.

\section{Conclusion}

The outreach training course is a new project of university sports. Its characteristic is to enhance the psychological quality and social adaptability in experiential activities. The development of open training courses in university sports teaching is in line with the needs of university personnel training. There is no doubt that outreach training can improve students' psychological quality. Outward training has obvious advantages in tapping its own potential, enhancing self-confidence, cultivating interpersonal relationships, and advancing problems. Extended training is a 
comprehensive activity that integrates education, sports, psychology, and social functions. Physical fitness, psychological quality, and social adaptability are all indispensable in outreach training. It is a useful attempt to fully implement quality education.

\section{References}

[1] Zhang Yupeng. Research on the application of self-efficacy theory in physical education teaching [J]. Teaching and Management. 2008 (24)

[2] Tong Zhaoyan, Sun Xiangbiao. Self-efficacy theory and its implications for teacher teaching [J]. Science and Technology Information. 2008 (16)

[3] Zhang Hui, Liu Xianglan. Analysis of the Related Factors in the Development of Outward Bound Training Courses in Colleges and Universities [J]. Journal of Sports Adult Education. 2006 (05)

[4] Zhang Fan. Research on Outward Bound Training for Improving the Team Spirit of Sports Team Athletes[J]. Journal of Beijing Sport University. 2006 (10)

[5] Zhang Jinguo. Research on the development of training courses in college sports teaching [J]. Journal of Wuhan Institute of Physical Education. 2006 (10) 